\title{
A Review on Psycho physiological impacts of yoga on Anxiety in undergraduate students
} Mr. Vikram Sharma,

\author{
Mr. Naveen Kumar Garg \\ D. M. College of Education, Moga
}

\begin{abstract}
Undergraduate students are defenseless against a basic period in formative development, confronting thorough scholastic work, and figuring out how to work autonomously. Physical exercises, for example, running and bicycling have been appeared to improve temperament and alleviate pressure. In any case, understudies regularly have low degrees of physical movement. Yoga is an antiquated physical and mental movement that influences temperament and anxiety. Be that as it may, considers looking at the psycho physiological impacts of yoga are uncommon in peer-checked on diaries. The point of this examination is to build up fundamental proof for the psycho physiological impacts of yoga on worry in youthful grown-up understudies. The current investigation proposes that yoga effect sly affects a psycho physiological level that prompts diminished degrees of worry in undergrad. Further research is expected to look at the degree to which various kinds of yogic practices address the necessities of various school subpopulations.
\end{abstract}

\section{INTRODUCTION}

About $40 \%$-half of undergrads are truly inert. So also, it was discovered that understudies' physical action has been genuinely disregarded as an examination point, there is an absence of various level methodologies (i.e., individual, psychosocial, and natural levels) for looking at physical action practices in the undergraduate students populace and proportions of physical action are emotional and conflicting which makes correlations of physical action designs among various examples troublesome or impossible.(Keating, Guan et al. 2005) Similarly, the accessible research shows that the predominance of stress is expanding among school students.(Whitehead and Corbin 1991) The past investigation revealed that yoga lessens menstrual issues and menstrual pain in female college understudies with essential dysmenorrhea.(Berger and Owen 1992) The psycho physiological changes that describe the viability of yoga for better pressure the board in understudies have not been concentrated sufficiently.

YOGA

Investment in physical action all the time is one of the essential factors in keeping up sound wellbeing in current society. Because of stationary way of life driving numerous wellbeing related issues, the commonness of physical latency among understudies calls for quick action.(Cruz, Fabian et al. 2013) Along with heart stimulating exercise and move, yoga is one of the most renowned physical action that school young lady understudy might want to lean toward as a choice. (Chong, Tsunaka et al. 2011) Physical action, for example, yoga is a key component in wellbeing advancement. The conventional articulations of yoga as a way of life is immovably attached in and focused on the exemplary writings (e.g., Yoga Sutra by Patanjali, Hatha Yoga writings like Hatha Yoga Pradeepika, Gheranda Samhita) and grasp the idea of the eight appendages, or angles, of yoga. In progressively explicit, the eight appendages are of incredible intrigue to yogis who look to hold fast to yoga as a philosophical establishment forever, instead of exclusively a physical practice.(Malathi and Damodaran 1999) Therefore, yoga is basically a craftsmanship and study of all encompassing living; a viable technique for improving wellbeing notwithstanding the anticipation and the executives of diseases.(Gopal, Mondal et al. 2011) Yoga diminishes worry through decreasing thoughtful activity (Bhat, Jain et al. 2016); (Yang and Kim 2016) and improves the feeling of general well-being. (Bandha 2008)

\section{Anxiety and College Student}

Anxiety influences understudies' physical, mental, social, and scholarly wellbeing. Understudy won't generally have the essential pressure the board abilities and adapting methodologies. Physical action is one adapting methodology that is maybe underutilized by numerous school students.(Kanojia, Sharma et al. 2013) Many orderly audits and various investigations on impacts on yoga for anxiety the executives in understudies uncovered constructive outcomes of yoga (as a brain body mediation) on stress decrease in school student (Thangavel, Gaur et al. 2014);(Goldstein, Lewis et al. 2016);(Brems, Colgan et al. 2016).

\section{Physiological Impacts of Yoga in Undergraduate Students}

Yoga holds potential as a self-enabling, no pharmacological strategy for upgrading pressure the board, and health in school students.(Sengupta 2012) It was accounted for that Pranayama preparing diminishes thoughtful action, bringing about mental unwinding and diminished autonomic excitement in this manner, 
diminishing power variances during isometric constriction. This was reflected as progress close by hold quality and continuance in clinical students.(Vempati and Telles 2002). In one examination planned for exploring the impact of incorporated yoga on autonomic parameters and mental prosperity during both pre-and post-periods of menstrual cycle in sound youthful female controls, it was seen that there was a huge modification of autonomic capacities and mental status in premenstrual stage when contrasted and postmenstrual stage in youthful solid females. What's more, it was uncovered that standard act of yoga effect sly affects the two periods of menstrual cycle by bringing parasympathetic strength and mental prosperity most likely by adjusting neuro-endocrinal axis.(Udupa, Bhavanani et al. 2003).

\section{Mental impacts of yoga in undergraduate students}

It was seen that Suryanamaskara, a yogic practice was compelling in prompting unwinding demeanors, for example, physical unwinding, mental calm, quiet/harmony, refreshed and revived, quality and mindfulness and happiness and lessens sluggishness, substantial pressure, stress and antagonistic feeling at a dispositional level.(Rocha, Ribeiro et al. 2012) Yogic practices assume a significant job in improving passionate sensitivity,(Godse, Shejwal et al. 2015) continued attention,(Ganpat, Dash et al. 2014) mental performance,(Sheela and Ganpat 2013) and parity character trait (Ganpat, Nagendra et al. 2013) among understudies, in this way making ready for their scholastic greatness. Yoga additionally decreases apparent pressure and negative effects in undergrads in this manner improving mental prosperity in them.

\section{Recommended proof based yoga treatment convention for undergraduate students}

In light of clinical administration and psycho physiological impacts of yoga in understudies, the recommended proof based yoga treatment for undergrads may incorporate after yogic practices:(Tikhe, Nagendra et al. 2012); (West, Otte et al. 2004)

$>$ Starting Prayer.

$>$ Kapalbhati Kriya, Agnisar Kriya.

$>$ Hands in and out breathing, hands stretch breathing, lower leg stretch relaxing.

$>$ Jogging, forward and in reverse bowing, side bowing, winding.

$>$ Surya namaskar (greeting to the sun practice).

$>$ Tadasan (palm tree present), Vrikshasana (tree present), Padahastasan, Ardha Chakrasana, Bhujangasana, Shalabhasana.

$>$ Quick relaxation technique.

$>$ Nadi Shuddhi Pranayama, Sheetali Pranayama, Seetkari Pranayama, Bhramari Pranayama.

$>$ Om Meditation.

$>$ Closing Prayer.

\section{CONCLUSION}

The current survey study recommends that yoga productive affects psycho physiological level that prompts expanded scholastic execution in understudy. Further research on the connection between yoga practice and undergrads is justified to affirm the viability of yoga and to remember it for the schedule of the undergraduate students.

\section{REFERENCE}

1. Bandha, S. S. A. P. M. (2008). Munger, Bihar, India: Yoga Publications Trust.

2. Berger, B. G. and D. R. Owen (1992). "Mood alteration with yoga and swimming: aerobic exercise may not be necessary." Perceptual and Motor skills 75(3_suppl): 1331-1343.

3. Bhat, N., et al. (2016). "Prevalence and characteristic of headache in dental professionals: a questionnaire based survey." Journal of clinical and diagnostic research: JCDR 10(4): ZC107.

4. Brems, C., et al. (2016). "Elements of yogic practice: Perceptions of students in healthcare programs." International journal of yoga 9(2): 121.

5. Chong, C. S., et al. (2011). "Effects of yoga on stress management in healthy adults: a systematic review." Alternative therapies in health and medicine 17(1): 32.

6. Cruz, S. Y., et al. (2013). "Physical activity and its associations with sociodemographic characteristics, dietary patterns, and perceived academic stress in students attending college in Puerto Rico." Puerto Rico health sciences journal 32(1).

7. Ganpat, T. S., et al. (2014). "Yoga therapy for promoting emotional sensitivity in University students." Journal of education and health promotion 3.

8. Ganpat, T. S., et al. (2013). "Efficacy of yoga for mental performance in university students." Indian journal of psychiatry 55(4): 349.

9. Godse, A. S., et al. (2015). "Effects of suryanamaskar on relaxation among college students with high stress in Pune, India." International journal of yoga 8(1): 15. 
10. Goldstein, M. R., et al. (2016). "Improvements in well-being and vagal tone following a yogic breathingbased life skills workshop in young adults: Two open-trial pilot studies." International journal of yoga 9(1): 20.

11. Gopal, A., et al. (2011). "Effect of integrated yoga practices on immune responses in examination stress-A preliminary study." International journal of yoga 4(1): 26.

12. Kanojia, S., et al. (2013). "Effect of yoga on autonomic functions and psychological status during both phases of menstrual cycle in young healthy females." Journal of clinical and diagnostic research: JCDR 7(10): 2133.

13. Keating, X. D., et al. (2005). "A meta-analysis of college students' physical activity behaviors." Journal of American College Health 54(2): 116-126.

14. Malathi, A. and A. Damodaran (1999). "Stress due to exams in medical students-a role of Yoga." Indian journal of physiology and pharmacology 43: 218-224.

15. Rocha, K., et al. (2012). "Improvement in physiological and psychological parameters after 6 months of yoga practice." Consciousness and cognition 21(2): 843-850.

16. Sengupta, P. (2012). "Health impacts of yoga and pranayama: A state-of-the-art review." International journal of preventive medicine 3(7): 444.

17. Sheela, H. R. R. N. and T. S. Ganpat (2013). "Efficacy of Yoga for sustained attention in university students." Ayu 34(3): 270.

18. Thangavel, D., et al. (2014). "Effect of slow and fast pranayama training on handgrip strength and endurance in healthy volunteers." Journal of clinical and diagnostic research: JCDR 8(5): BC01.

19. Tikhe, S. G., et al. (2012). "Ancient science of yogic life for academic excellence in university students." Ancient science of life 31(3): 80.

20. Udupa, K., et al. (2003). "Effect of pranayam training on cardiac function in normal young volunteers." Indian journal of physiology and pharmacology 47(1): 27-33.

21. Vempati, R. and S. Telles (2002). "Yoga-based guided relaxation reduces sympathetic activity judged from baseline levels." Psychological reports 90(2): 487-494.

22. West, J., et al. (2004). "Effects of Hatha yoga and African dance on perceived stress, affect, and salivary cortisol." Annals of Behavioral Medicine 28(2): 114-118.

23. Whitehead, J. R. and C. B. Corbin (1991). "Youth fitness testing: The effect of percentile-based evaluative feedback on intrinsic motivation." Research Quarterly for Exercise and Sport 62(2): 225-231.

24. Yang, N.-Y. and S.-D. Kim (2016). "Effects of a yoga program on menstrual cramps and menstrual distress in undergraduate students with primary dysmenorrhea: a single-blind, randomized controlled trial." The Journal of Alternative and Complementary Medicine 22(9): 732-738. 